\title{
Core Competencies for Undergraduates in Bioengineering and Biomedical Engineering: Findings, Consequences, and Recommendations
}

\author{
John A. White, ${ }^{1}$ Donald P. Gaver $0{ }^{2}{ }^{2}$ Robert J. Butera Jr., ${ }^{3}$ Bernard Choi, ${ }^{4}$ Mary J. Dunlop, ${ }^{1}$ \\ K. Jane Grande-Allen, ${ }^{5}$ Anna Grosberg, ${ }^{4}$ Robert W. Hitchcock, ${ }^{6}$ Aileen Y. Huang-Saad, ${ }^{7}$ \\ Mitri Kotche, ${ }^{8}$ Aaron M. Kyle, ${ }^{9}$ Amy L. Lerner, ${ }^{10}$ John H. Linehan, ${ }^{11}$ Robert A. Linsenmeier, ${ }^{11}$ \\ Michael I. Miller, ${ }^{12}$ Jason A. Papin, ${ }^{13}$ Lori Setton, ${ }^{14}$ Allyson Sgro, ${ }^{1}$ Michael L. Smith, ${ }^{1}$ \\ Muhammad Zaman, ${ }^{1}$ and Abraham P. LeE ${ }^{4}$ \\ ${ }^{1}$ Department of Biomedical Engineering, Boston University, Boston, MA, USA; ${ }^{2}$ Department of Biomedical Engineering, \\ Tulane University, New Orleans, LA, USA; ${ }^{3}$ Wallace H. Coulter Dept. of Biomedical Engineering, Georgia Institute of \\ Technology, Atlanta, GA, USA; ${ }^{4}$ Department of Biomedical Engineering, University of California - Irvine, Irvine, CA, USA; \\ ${ }^{5}$ Department of Bioengineering, Rice University, Houston, TX, USA; ${ }^{6}$ Department of Biomedical Engineering, University of \\ Utah, Salt Lake City, UT, USA; ${ }^{7}$ Department of Biomedical Engineering, University of Michigan, Ann Arbor, MI, USA; \\ ${ }^{8}$ Department of Bioengineering, University of Illinois-Chicago, Chicago, IL, USA; ${ }^{9}$ Department of Biomedical Engineering, \\ Columbia University, New York, NY, USA; ${ }^{10}$ Department of Biomedical Engineering, University of Rochester, Rochester, NY, \\ USA; ${ }^{11}$ Department of Biomedical Engineering, Northwestern University, Evanston, IL, USA; ${ }^{12}$ Department of Biomedical \\ Engineering, The Johns Hopkins University, Baltimore, MD, USA; ${ }^{13}$ Department of Biomedical Engineering, University of \\ Virginia, Charlottesville, VA, USA; and ${ }^{14}$ Department of Biomedical Engineering, Washington University in St. Louis, St.
} Louis, MO, USA

\begin{abstract}
This paper provides a synopsis of discussions related to biomedical engineering core curricula that occurred at the Fourth BME Education Summit held at Case Western Reserve University in Cleveland, Ohio in May 2019. This summit was organized by the Council of Chairs of Bioengineering and Biomedical Engineering, and participants included over 300 faculty members from $100+$ accredited undergraduate programs. This discussion focused on six key questions: QI: Is there a core curriculum, and if so, what are its components? QII: How does our purported core curriculum prepare students for careers, particularly in industry? QIII: How does design distinguish $\mathrm{BME} / \mathrm{BIOE}$ graduates from other engineers? QIV: What is the state of engineering analysis and systems-level modeling in $\mathrm{BME} / \mathrm{BIOE}$ curricula? QV: What is the role of data science in $\mathrm{BME} / \mathrm{BIOE}$ undergraduate education? QVI: What core experimental skills are required for BME/BIOE undergrads? s. Indeed, BME/BIOI core curricula exists and has matured to emphasize interdisciplinary topics such as physiology, instru-
\end{abstract}

\footnotetext{
Address correspondence to John A. White, Department of Biomedical Engineering, Boston University, Boston, MA, USA. Electronic mail: jwhite@bu.edu and Donald P. Gaver, Department of Biomedical Engineering, Tulane University, New Orleans, LA, USA. Electronic mail: donald.gaver@tulane.edu and Abraham P. Lee, Department of Biomedical Engineering, University of California - Irvine, Irvine, CA, USA. Electronic mail: aplee@uci.edu
}

mentation, mechanics, computer programming, and mathematical modeling. Departments demonstrate their own identities by highlighting discipline-specific sub-specialties. In addition to technical competence, Industry partners most highly value our students' capacity for problem solving and communication. As such, BME/BIOE curricula includes open-ended projects that address unmet patient and clinician needs as primary methods to prepare graduates for careers in industry. Culminating senior design experiences distinguish $\mathrm{BME} / \mathrm{BIOE}$ graduates through their development of client-centered engineering solutions to healthcare problems. Finally, the overall BME/BIOE curriculum is not stagnant - it is clear that data science will become an ever-important element of our students' training and that new methods to enhance student engagement will be of pedagogical importance as we embark on the next decade.

Keywords-Biomedical Engineering Curriculum, Biomedical Engineering Education, Biomedical Engineering Design, Biomedical Engineering Research.

\section{INTRODUCTION}

In recent years, the number of undergraduate degrees earned in Biomedical Engineering (BME) and Bioengineering (BIOE; we will use these terms inter- 
changeably) has grown explosively to well over 5,000 degrees earned per year (source: ASEE). Our team-led discussions focused on the degree to which accredited undergraduate programs had converged on a core curriculum and probed the efficacy of these programs in several regards. We considered six questions in a plenary talk, and break-out sessions, as described below.

QUESTION I: IS THERE A CORE CURRICULUM, AND IF SO, WHAT ARE ITS COMPONENTS? (PLENARY: DR. LINSENMAIER; BREAKOUT: DRS. GRANDE-ALLEN, MILLER, AND ZAMAN)

The plenary talk "The de facto core curriculum in BME and BIOE," provided an historical perspective to the question of the existence of a core curriculum. This discussion began in 1991 with representatives of 19 accredited programs convening at Wright State University. A brief report indicated that there were common elements of the curricula at that time. Discussions about the core elements of the undergraduate curriculum have continued since, especially at the three subsequent BME Education Summit meetings, the last one occurring in Chicago in 2008.

The most extensive study of the core curriculum was carried out by the VaNTH (Vanderbilt-NorthwesternTexas-HST) ERC in Bioengineering Educational Technologies in 2004 and updated in 2013. A survey of BioE and BME programs for the fourth Summit Meeting in 2019 supplemented and updated this again. These surveys demonstrated that a core undergraduate curriculum exists, with differences occurring in the form of elective engineering courses. We define the consistent core curriculum by those courses required by at least $75 \%$ of ABET accredited programs, and this has been consistent since 2004. In order of prevalence this includes:

- Freshman engineering (sometimes but not always focused on BME),

- BME capstone design,

- Physiology,

- Mechanics,

- Additional biology (usually cell and molecular),

- Circuits and instrumentation,

- Computing,

- Statistics,

- Materials,

- Fluid mechanics and transport, and

- Signal analysis.

Clearly the BME curriculum is distinct and does not resemble that of any other engineering field. Instead, as befits an interdisciplinary field, the BME core includes a hybrid of key elements of several fields, plus a heavy dose of biology. Data from the VaNTH project showed that faculty and industry participants largely agreed on the relative importance of individual concepts that should be in the undergraduate curriculum. As expected from the existing curriculum, important concepts were identified in many areas, and those related to statistics and measurements were among the most important.

Break-out sessions delved into data collected from the curriculum survey, and the factors that are influential in driving a particular curricular makeup for an institution.

\section{Depth}

These data indicated that the following content depth was consistent:

- 5-8 credit-hours: quantitative physiology, instrumentation, and computer programming.

- 1-4 credit-hours: quantitative molecular/cell biology, statistics, signal processing, solid mechanics, transport, and biomaterials.

- Inconsistent: Organic chemistry, tissue engineering, control systems, and fluid mechanics were not mandatory in a significant number of programs.

Leaders also presented data that the most common lab courses were Instrumentation (almost 90\%). Physiology $(>50 \%)$, and Mechanics (just $<50 \%$ ), with Molecular Biology Labs and Advanced Chemistry Lab being less common.

\section{Correlation Between Courses}

Statistical analyses were used to examine the clustering of particular courses, which demonstrated that there were several significant Spearman correlations between the degrees to which certain courses were offered. A Principal Components Analysis (PCA) demonstrates that the majority of the variability in the data was due to the degree to which either Computer Programming, Signal Processing, Controls, Solid Mechanics, and Transport are offered (F1, 23.8\% of variability), or to the degree to which Quantitative Cell and Molecular Biology, Tissue Engineering, and Biomaterials exist in a curriculum (F2, 14.54\% of variability).

The PCA showed correlations in the existence of courses in a specific department's curriculum:

High correlations:

- Instrumentation, Fluids, and Transport

- Signals, Solid Mechanics, Quantitative Physiology, and Control 
Low correlations:

- Biomaterials and Tissue Engineering, and

- Computer Programming and Quantitative Molecular and Cellular Biology.

Negative correlation:

- Biomaterials and Quantitative Molecular and Cellular Biology

However, this analysis showed that inter-institutional clustering does not exist across the two principal components. In other words, there is a wide range of variation in how different institutions choose to assemble their curriculum. The discussants speculated that the origins in the variability was due to several factors, including historical origins (e.g. the founding faculty came from different disciplines), variance based on size of the undergraduate class, the presence or absence of tracks, effects of double majors and other concentrations, differences in university requirements for free electives, and students' planned future trajectories.

\section{On-Boarding and Tracks}

During the break-out sessions, a rich discussion addressed additional issues related to students' entrance into the program, and modifications of core curricula in a dynamic biomedical engineering field. Real-time surveys showed that there is not a consistent pathway to attracting and retaining students to BME. In general students are expected to declare their major early, with the following distribution:

- 1 st semester: $32 \%$,

- 2nd semester: $20 \%$,

- 3rd semester: $38 \%$, and

- 4th semester: $8 \%$.

Slightly over half $(57 \%)$ of departments represented by attendees offering an Introduction to BME course for their first-year students. Those who offer this course believe it to be a good way to prepare their students for their advanced coursework and improve retention in the BME major.

Conversations focused on the benefits/drawbacks of tracks; for example, on whether tracks offer flexibility and rigor, or whether they are too restrictive. Surveys indicate that $45 \%$ of the attendees' institutions offer tracks, $32 \%$ do not, and $14 \%$ have an unofficial track organization. It was largely agreed that although the tracks can be challenging to offer consistently for smaller programs, they offer students a sense of community, shared interest groups and guidance.
Curriculum Modification in a Dynamic Field

Finally, participants discussed processes by which core curricula can be modified to address changes in the BME field. This led to the question 'how can newer areas of our research missions (such as more growth in synthetic biology and quantitative biology) become aligned with our teaching missions?' This question was unresolved, but it was recognized that undergraduate students who study these areas in the research lab are very interested in taking undergraduate courses on these topics. It is clear that as departments hire more faculty in cutting-edge areas outside of the conventional core curriculum, they must become integrated and tied to ABET outcomes.

\section{QUESTION II: HOW DOES OUR PURPORTED CORE CURRICULUM PREPARE STUDENTS FOR CAREERS, PARTICULARLY IN INDUSTRY? (BREAKOUT: DRS. HUANG-SAAD, LINEHAN, AND KOTCHE)}

\section{Pre-meeting survey results}

Surveys were distributed to industry engineer and manager liaisons of participating BME departments. The following responses were collected from the 150 respondents of the industry survey:

Major product of industrial respondants:

- MedTech: $76 \%$

- BioTech: $13 \%$

- Diverse (non-profit, consulting, software): $10 \%$

- No response: $1 \%$

The majority of survey respondents were from manufacturing divisions (66\%) and unfortunately none of the respondents were from research and development divisions.

Industry Survey respondents ranked 23 skills and competencies that positively influence bachelors-level hiring decisions from any engineering major. MedTech and BioTech respondents agreed with 8 of the top- 10 skills, and both sectors rated personal attributes higher than disciplinary skills. In order, the most important were considered:

1. problem-solving,

2. interpersonal communication,

3. design experience,

4. team projects,

5. writing,

6. technical presentation,

7. advanced courses in traditional engineering,

8. experience with relevant software, and

9. statistics. 
BioTech respondents also valued academic research experience and exposure to the life sciences.

In contrast, 71 respondents from 59 academic departments ranked the most essential elements of training for career paths in industry, graduate school or medical school. This survey did not replicate the industry survey, as it related to essential training included content knowledge topics but not skillsets focused on interpersonal skills, technical writing or presentation skills, for example. Academic respondents valued the following skills in order:

1. statistics,

2. programming skills,

3. design,

4. regulatory procedures,

5. biomaterials,

6. signal processing,

7. instrumentation,

8. quantitative biology, and

9. biomechanics.

\section{Meeting Discussion}

Groups of participants were asked to discuss and report responses to the following question: "What actions are being taken by your department to specifically prepare students for industry?"

Participants highlighted various ways that their BME programs seek to provide instruction and experience in the areas that Industry reports are critical considerations when hiring recent graduates. The main outcomes from these discussions were:

(a) While BME departments recognize the need to cultivate professional competencies, including interpersonal communication, teamwork, writing and presentation skills, the majority of departments do not leverage the "core curriculum" for these skills outside of the capstone design class. However, several departments shared novel approaches for teaching these competencies, including a "telling your story" course, outreach and BME education to local high schools, communications instructors coteaching with engineering faculty, professional development courses, project management certification, and teamed community service.

(b) Participants acknowledge that although the BME curriculum addresses professional competencies such as interpersonal skills and team work, they are not, in fact, explicitly taught. For example, it was stated that while courses have team-based projects, teaming is not the core competency emphasized.

(c) Design classes, and specifically the capstone design course, cannot be the "catchall" for developing a professional competency skillset for undergraduate engineering students. Practicing these skills repeatedly throughout the curriculum in multiple courses builds experience and competency. In addition, departments should consider explicitly teaching written and oral communication and collaboration prior to design courses.

(d) Are there best-practices that were identified? Did new questions arise from the discussions? What surprised you by the nature/results of the discussion? Attendees shared a number of approaches, but time limitations precluded making a comprehensive list. We recommend creating an online venue for sharing of near-best practices and recommendations.

Going forward, we recommend explicit instruction in professional competencies, including written communication, presentations, empathy, and teamwork, throughout the curriculum. We hypothesize that such training will strengthen biomedical engineering professional identity.

\section{QUESTION III: HOW DOES DESIGN DISTINGUISH BME/BIOE GRADUATES FROM OTHER ENGINEERS? (BREAKOUT: DRS. GILBERTSON, HITCHCOCK, AND LERNER)}

Three BME design related content areas were used to query the session attendees:

(1) interdisciplinary medically focused knowledge;

(2) standards and regulations; and

(3) the business of medical technology.

During the meeting, four questions were discussed in groups of 5-8 participants. These questions elicited insight into how BME design differentiates BME graduates from other engineering disciplines. Common answers to the four questions were as follows:

1. What are BME departments good at teaching? Respondents noted that our students are particularly strong in

- interdisciplinary knowledge $(28 \%)$,

- communication (17\%),

- understanding client needs $(13 \%)$, 
- understanding human anatomy and physiology $(12 \%)$,

- understanding biological constraints (12\%), and

- interactions with clinicians $(11 \%)$.

It is worth noting that these strengths match up well with the needs of the industry (see How does our purported core curriculum prepare students for careers, particularly in industry?).

2. What are areas need attention? This list included specific skills including design for:

- manufacturing (17\%),

- verification and validation (14\%),

- tinkering experience $(14 \%)$,

- data science exposure $(14 \%)$,

- fabrication technologies $(13 \%)$,

- applications of models to projects $(13 \%)$,

- experience with fabrication technologies (13\%), and

- establishment of industry contacts (12\%).

3. What practices can we share? Respondents noted several readily shareable practices, including ways to:

- implement interdisciplinary teams (18\%),

- regulatory education $(16 \%)$,

- case studies $(15 \%)$, and

- methods to assess the needs of end users (11\%).

4. How can we market our distinctions to industry and others? Respondents answered this question broadly. Common answers included

- emphasizing interdisciplinary knowledge of students $(20 \%)$,

- hosting showcase design events (16\%),

- emphasizing industry involvement in senior design $(14 \%)$,

- showcasing the field as a bridge between disciplines $(13 \%)$,

- requiring real deliverables for "real problems" (presumably as defined by clients in medicine or industry $(13 \%)$, and

- developing a better understanding of the patient/ provider system $(12 \%)$.
Generally, these results point to several strengths that we and our students should emphasize to potential employers. In particular, practical-training elements should be emphasized more, and there is a pressing need for more formal collaboration in sharing best practices.

\section{QUESTION IV: WHAT IS THE STATE OF ENGINEERING ANALYSIS AND SYSTEMS-LEVEL MODELING IN BME/ BIOE CURRICULA? (BREAKOUT: DRS. BUTERA, CHOI, AND DUNLOP)}

The goal of these break-out sessions was to gather diverse ideas and generate discussion about engineering analysis and systems-level modeling in BME/BIOE curricula. Each session included a poll, asking participants the number of required semester credit hours devoted to signal processing, controls, and quantitative physiology. Of these three subjects programs required the following: quantitative physiology (95\%), Signal processing $(85 \%)$, and Control systems $(50 \%)$.

The discussion began with a purposefully divisive question: 'Should BME/BioE students have the same level of systems-level modeling and engineering analysis in their coursework as students in other engineering majors (e.g. ME, EE)?'According to their answers (yes, no, somewhere in between), the audience was split into groups for subsequent discussion.

The rest of the sessions revolved around three questions:

1. How do we define systems level modeling?

2. What type of competencies should BME students have in this area? What is the relative importance of modeling related to the design of biological systems, vs. understanding and controlling biological processes?

3. What is your recommendation for integration of systems-level modeling into a general $\mathrm{BME} / \mathrm{BioE}$ curriculum? If your curriculum currently does not have a core required course in this topic, which required class in your curriculum would you remove?

Much of the subsequent discussion revolved around defining core competencies. Major topics in this discussion included:

- Input/output thinking and how to quantify $\mathrm{I} / \mathrm{O}$ relationships (useful for design and understanding)

- Conveying an appreciation of biological complexity 
- Knowing what level of complexity to use to solve a problem (and the limitations of $\mathrm{I} / \mathrm{O}$ thinking for some problems)

- Working with noisy and imperfect data, and the importance of model validation

- Programming skills

- Transitioning the dominant pedagogy from using models to developing and refining models

A second important discussion topic was that of how to integrate systems modeling into an undergraduate curriculum. In most departments, modeling was typically taught as a tool for understanding biological systems. Most agreed that it would be helpful to students to move toward using modeling to understand the operating principles of biological systems.

\section{QUESTION V: WHAT IS THE ROLE OF DATA SCIENCE IN BME/BIOE UNDERGRADUATE EDUCATION? (BREAKOUT: DRS. PAPIN, SETTON, AND SGRO)}

The goal of this breakout was to discuss how we could best implement data science training in our curricula, and to identify what expertise employers expect in data science from BME undergrads.

Moderators began by introducing the topic, and recommending that participants read a public-domain report from the NAS, NAE, and NAM (https://doi. org/10.17226/25104). From that presentation and subsequent discussion, the moderators and participants reached three main conclusions:

- Data science covers a broad range of topics including data collection, integration across datasets, visualization, storage, and analysis. Many of these topics are already covered in our existing coursework but are not branded as part of data science.

- There is a large industry need for data scienceeducated college graduates. Many major employers of BME undergraduates, as well as startups, need these skills in their employees.

- In general, BME students are not going to be developing new data science analysis methods. The major value of educating BME students in data science is that they can bring their domain-specific understanding of biomedical data collection, analysis and interpretation, in order to provide meaningful use of these data sets.

The next moderated discussion focused on four questions:
1. Do each of these topics in data science map on to a unique domain area in BME? What data science topics and applications are BME undergraduates uniquely poised to excel in due to their domain specific skill set?

2. Is there any data science topic that should be taught regardless of the domain expertise required?

3. What models of education make sense for educating BME students in data science?

4. How can we brand data science education so that it is attractive to employers? What specific data science skills are employers looking for in BMEeducated college graduates?

Although the value of education in data sciences was appreciated by all, to-date most departments have not made much progress, and the discussion did not result in a consensus set of best practices. However, many participants favored having a data science or a probability, statistics, and data science course, followed by a capstone project that integrates data science as a major feature. Such an element of capstone design would allow students to gain experience across all the different topics that are part of a complete data science education beyond data analysis, potentially including ethics and related challenges such as dealing with sparse data or the appropriate ways of integrating disparate data sets.

The discussion left participants with many excellent, open questions to consider, including the following:

- Is this a good topic for a follow-up 1-year master's degree?

- Is one course in data science sufficient for most BME undergrads?

- What approaches can we take to make room in our curricula for data science? Examples given included allowing more use of AP credit to satisfy humanities requirements, tailoring design courses to include more data science projects, and fitting data science into other existing courses like systems modeling.

- What information could BMES as a professional society collect and offer to help BME/BIOE programs make informed decisions about how to work data science into their offerings?

- What body should develop a code of ethics for data science in BME? (e.g., Council of Chairs, BMES, ASEE)

- What data could BMES facilitate sharing of between institutions to help inform these decisions?

- What training will current BME/BIOE faculty need to support inclusion of data science in core undergraduate $\mathrm{BME} / \mathrm{BIOE}$ courses? 


\section{QUESTION VI: WHAT CORE EXPERIMENTAL SKILLS ARE REQUIRED FOR BME/BIOE UNDERGRADS? (BREAKOUT: DRS. KYLE, GROSBERG, AND SMITH)}

All ABET accredited BME departments have lab/experimental components to courses in the required curriculum. However, the content of these lab courses varies greatly program-to-program. This breakout session sought a consensus on what components were considered essential skills gained by an undergraduate BME student.

Based on the survey administered during the summit, there is absolute agreement that experimental experience is essential. The average time as a percentage of total curriculum was $27 \pm 13 \%$ with a minimum suggestion of $8 \%$ devoted to labs $(n=51)$.

The goal of these breakouts was to determine what core experimental skills are required, or should be required, for undergraduate biomedical engineering students. Specifically, information was sought about common lab/experimental education at BME undergraduate programs; best practices for content, pedagogy, assessment and evaluation; and ascendant topics in BME that should be part of modern lab courses. The breakouts revolved around the central questions listed below, posed to the participants and also submitted to all symposia attendees later.

1. What lab/experimental skills define a BME undergraduate? This critical question led to a robust discussion amongst the session participants. A major outcome that arose from both of the breakouts is that there is no specific hard/technical skill set that is considered universally appropriate for all BME undergraduates. Instead, the skills that were conventionally regarded are 'soft' skills, particularly: experimental design and planning, data acquisition and analysis skills, and hypothesis testing were considered typical of BME undergraduates. Coupled with these considerations is an emphasis on BMEs having the ability to perform and analyze measurements from living systems. It was proposed that the multi-faceted nature of these sorts of measurements sets the BME undergraduate apart from students in any other engineering discipline. While the attendees could not reach a consensus on specific technical skills that are critical for BME undergraduates, the survey provides some indication of the relevance of specific skills within laboratory courses. It is noteworthy that the skill most categorized as Critical/Very Important pertains to data analysis, aligning with the experimentation/data analysis emphasis identified by the session participants.
This was an interesting finding, given that there is little consensus on how to teach this topic (see Question V). Respondents rarely indicated that any technical skills were unimportant, which reflects a diversity of opinions on what 'hard' skills should be included in BME lab courses.

2. Should labs be explicitly defined, open-ended, both? There was a general consensus that students should be exposed to an open-ended lab component at some point in the curriculum. But there exists a spectrum of mechanisms for exposing students to such problems. One popular proposed approach entailed scaffolding via introduction to basic skills and concepts, culminating in openended, hands-on labs. Alternatively, it was proposed that labs be the domain for learning and applying basic skills, while the less explicitlydefined challenges arise in subsequent advanced and/or specialized courses. Similarly, the timing of when more advanced challenges ranged amongst the participants; some felt that open ended problems may be better suited later in the curriculum. However, this would largely be informed by skills learned in initial laboratory courses, which the majority of respondents asserted should take place during the first two years of undergraduate study.

3. Should the students build something (design, fabrication skills)? The participants overwhelmingly and resoundingly agreed that students should build something within the context of the laboratory. Participants differentiated between building a device utilizing explicit guidance (i.e., a cookbook approach to building a device with a well-defined outcome), as opposed to innovative design and fabrication of a device or tool. Fabrication, including constraints on fabricating tools or devices, was strongly supported as a curricular topic in BME lab courses.

4. How often (and how) should lab courses be updated? The majority of the respondents indicated that they are annually revising their laboratory courses. The assessment and revision of laboratory courses are informed by a number of different mechanisms. Participants indicated that revisions are done with the goal of continuous improvement of courses, and indicated that the content in updated laboratory courses is often informed by input from Industrial Advisory Boards or alumni surveys. However, they made it clear that lab revisions are rarely guided by modern and/or groundbreaking research findings being translated into the classroom.

The following preliminary conclusions resulted from the breakout sessions: 
- The strengths of BME lab courses are their emphasis on training undergraduates in experimental design and data analysis/presentation skills especially as it applies to living systems.

- There is no consensus on specific technical skills that should be learned by students in these courses.

- Lab courses should arise fairly early in the BME curriculum, likely during Years 1 or 2 of undergraduate study.

While these are good starting points, it would be premature to use these data to define best practices. These data provide only preliminary data for use in a more robust study, wherein BME undergraduate departments throughout the country would be examined for their laboratory course(s) structure and content. In addition to the experimentalist skills that are currently emphasized, a study of undergraduate labs should strive to define a core set of technical competencies that can be used to better define the BME undergraduates' skillset.

Publisher's Note Springer Nature remains neutral with regard to jurisdictional claims in published maps and institutional affiliations. 